\title{
Place, space, and health inequalities
}

\author{
Jamie Pearce, Rich Mitchell, \\ and Niamh Shortt
}

\subsection{Introduction: Why is it important to think geographically?}

International evidence demonstrates strong, and rising, geographical inequalities in health on a range of spatial scales, from between countries to across neighbourhoods in the same city. In the UK, the socio-spatial patterning in health outcomes has been documented for over 150 years, beginning with the work of nineteenth-century social scientists, political theorists, and social reformers such as Engels, Chadwick, and Rowntree (Pearce and Dorling 2009). Geographical inequalities in health across parliamentary constituencies fell during the period from the early 1920s to early 1970s (Thomas et al 2010), but since the 1970s there has been a sharp increase in spatial inequalities in health in the UK; by 2007 health inequalities were as substantial as any time since the economic depression of the 1930s. The difference between the highest and lowest life expectancy across local authorities in the UK is around 14 years (Figure 14.1). Examining the geographical patterning of health is likely to be productive, as it can help to reveal societal, political, and environmental antecedents for health inequalities.

\subsubsection{Researching geographical inequalities in health}

Much has been written on health inequalities by academics from geography, sociology, epidemiology, and public health, and some of this work has adopted a spatial framework to consider geographical explanations for the ubiquitous rise in health inequalities. In the broadest sense, within the field of health inequalities, three interrelated areas of geographical scholarship can be identified. 


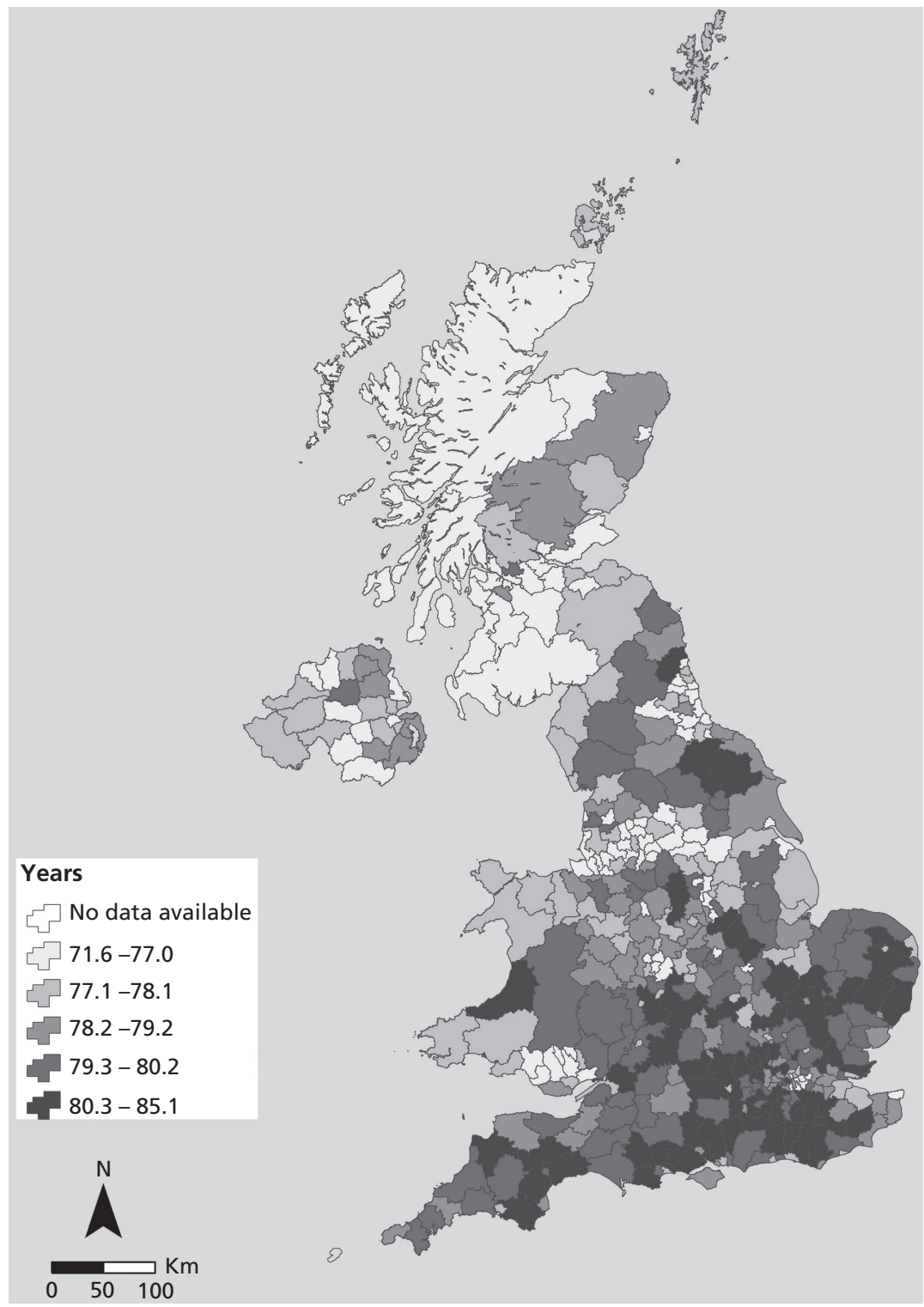

Fig. 14.1 Male life expectancy at birth (years) by UK local authorities 2008-2010.

Data from Life expectancy at birth and at age 65 by local areas in the United Kingdom, 2006-08 to 2010-12, Office of National Statistics, 2014. 
First, the neighbourhoods and health literature emphasizes that local circumstances can be important in understanding residents' health. Drawing on socioecological theory, it is argued that where you live, work, and play, as well as who you are, matters for your health, and that 'place' explains a component of this socio-spatial arrangement. Galster (2011) suggests neighbourhood influences can be split into four broad rubrics: social interactive mechanisms (social processes such as the collective norms or networks and cohesion between residents); environmental mechanisms (physical attributes such as the public infrastructure, and exposure to toxic substances); geographical mechanisms (particularities of areas relating to macro-level political and economic factors, such as limited local tax base or restricted job opportunities); and institutional mechanisms (actions of those external to the neighbourhood which may result in place-based stigmatization or unequal public and private investment). A large body of work, often using multilevel modelling, distinguishes between 'contextual' and 'compositional' accounts for geographical variations in health. It is argued that place exerts an influence on a range of health outcomes (e.g. mortality, cancer incidence) and related behaviours (e.g. smoking, nutrition, and alcohol consumption).

However, neighbourhood explanations of health inequalities have been criticized for providing a partial account for inequalities in health across local areas (Pearce 2013). Most studies rely on cross-sectional associations, and there are few attempts to develop longitudinal study designs which are better suited to identifying causal processes (see Chapter 2). As the human geography literature has long recognized, neighbourhoods are fluid and non-bounded, and their make-up partially reflects broader macro-level social and economic processes that have accumulated over many years and decades (Wacquant 2008). Few studies have tracked and explained the historical development of neighbourhoods, and then considered the repercussions for local health and well-being. This approach offers opportunities not only to identify causal relationships, but also to better understand the ways in which local neighbourhoods can mediate between structural drivers (social, political, and environmental factors) and inequalities in health.

Second, work on environmental justice and health inequalities has been helpful in emphasizing that place and environment are socially produced and that there are material effects of these arrangements, including health (Rosenberg 2014). Environmental and social differences are inextricably connected. From a health inequalities perspective, this work has demonstrated that the social and spatial distribution of environmental 'goods' and 'bads' affects the socio-spatial distribution of health and well-being. For instance, socially disadvantaged neighbourhoods often suffer from the 'triple jeopardy' of poor environmental quality (e.g. higher levels of ambient air pollution levels), high mortality and 
morbidity levels, as well as the many aspects of multiple deprivation (Pearce et al 2010). Importantly, environmental justice framing encourages researchers to identify the social and political processes underlying this geographical arrangement, as well as the implications for health and well-being.

Third, work on mobility and migration has been instructive (Gatrell 2011). In particular, the work on health-selective movements of people within and between countries, and the socio-political drivers of these processes, have demonstrated a tendency for 'healthy' populations to migrate to similar places (e.g. from the north to south of the UK). These movements can therefore partially explain the unequal geographies of health at various spatial scales. For instance, New Zealand research demonstrated that the differential migration of smokers and non-smokers since the 1970s has strongly affected the country's increasingly uneven social geographies of health (Pearce and Dorling 2010). Other migration-health inequalities work has pointed to the effects of migration on stress and mental health (of those that move and those remaining behind), migration as a vector for spreading disease, the implications of large-scale migration streams for health care provision, and monitoring the long-term implications of moving between highly distinct societies (e.g. adopting local risk factors and health profiles).

These three approaches have helped to explicate a number of geographical processes that are significant in understanding socio-spatial inequalities in health, but there is scope for further work using geographical frameworks to reveal how environmental processes combine with social and political concerns to establish and perpetuate health inequalities. We identify three areas in particular. First, geographical accounts of health inequalities have tended not to consider environmental concerns that have been typically examined outside the public health sphere. Yet human health emerges from complex systems and is affected by broader ecosystems that include multiple ecologies. These concerns are especially salient during a period of anthropogenic-driven environmental change. Second, whilst it is well recognized that spatial context matters for health, the historical context that is critical to understanding contemporary geographical processes (i.e. time) is rarely considered in public health work. Third, few studies have examined how social and physical environments can support good health and narrow health inequalities. It is plausible that environmental processes can disrupt the well-established links between material factors, health, and inequalities. The rest of this chapter uses a geographical framework to explore these three emergent, and interrelated, research areas that offer promise in understanding socio-spatial inequalities in health, moving us beyond the limitations of current approaches to studying health inequalities (see Chapters 6-9, 13, and 16-17). 


\subsection{Ecological public health}

Whilst public health was historically developed on the ideology of a social model of health, more recently there has been a policy shift towards a 'new' public health, with agency/the individual and behavioural change at the centre. Policy now appears to focus less on 'public' health and more on 'individual' health (Katikireddi et al 2013). This places us in the middle of what has been termed a 'lifestyle drift' (see Chapter 8). This drift has been in direct response to changing risks and health problems, for example a rise in lifestyle-related risks such as tobacco and alcohol consumption, coupled with health outcomes such as cancer and cardiovascular disease. Individuals do not exist in isolation, but rather in particular places and environments. Whilst such interventions recognize changing risks at the individual level, they fail to recognize parallel changes to risk within the environment. Furthermore, working within such linear systems of cause and effect fails to acknowledge the complex causal processes occurring 'in the real world' (Dean 1993, p. 29).

The challenges we now face, including increasing health inequalities and global environmental change, have been referred to as 'wicked issues' (Hunter 2009) due to their innate complexity (with tangled webs of interconnected nodes and pathways) and the consequent lack of simple, linear solutions. From a complex systems perspective, this means we need to be alert to the possibility that the impacts of particular changes may be nonlinear, unpredictable, and 'messy'. Within health inequalities research, complexity thinking has so far been lacking (Dean 1993), but it can help to move us beyond simple linear models of health outcomes (e.g. change behaviours to improve health and reduce health inequalities) towards seeing such outcomes as situated within dynamic systems, driven by a multitude of factors.

Addressing the challenge of complexity, Rayner and Lang (2012) present a model of Ecological Public Health (EPH). EPH emerged in the 1980s, responding to broader environmental risks for public health such as climate change and environmental hazards. Recognizing that people coexist with the natural environment, the concept focuses on the complex processes, environmental and social, that create and shape health. Individuals are not separated from their environment; human health is instead seen as part of a broader ecosystem that includes four broad environmental dimensions: material, biological, cultural, and social. EPH is currently being proposed as a 'new wave' of public health (Hanlon et al 2011), though EPH in itself may not offer anything new to public health researchers who have been engaging with similar broader socioecological theories such as those proposed by Bronfenbrenner (1979) and Dahlgren and Whitehead (1991). EPH does, however, remind us of the 
importance of the environment at a time of great environmental change. It also pushes us to explore not only the environmental determinants of health inequalities, but also the underlying mechanisms that drive these determinants. Such mechanisms illustrate the interrelationships between the broader macrolevel social and economic processes highlighted earlier. In this context, whilst not new, EPH offers a framework for researchers to engage with these challenges that moves us beyond a bio-reductionist approach (Rayner 2009). Exploring the interactions between all elements of the system, individual and environmental, will help us to understand the complexities and interrelationships of multiple variables 'viewing health as a process nested in contexts rather than as a static attribute of individuals' (McLaren and Hawe 2005, p. 9).

Reflecting these temporal and spatial concerns, the environmental determinants of health inequalities are diverse, including factors from each of the four broad EPH dimensions. These environmental determinants of health inequalities have become increasingly complex in an age of globalization and environmental change. Given this complexity, it is unsurprising that interventions that focus on changing individual behaviours have been shown, paradoxically, to increase the very same health inequalities they aim to reduce; a phenomenon known as the 'inequality paradox' (Buck and Frosini 2012). It is the explicit recognition of these environmental determinants of health inequalities in EPH that could encourage public health researchers to broaden their scope. We urge a return to concern for the social/environmental system as a whole, the inclusion of complexity into our empirical work, and better integration of research and data across both proximal and distal environments.

\subsection{Life course and place}

As Chapter 1 outlines, life course perspectives have made an important contribution to health inequalities research over the past 20 years. However, those with an interest in place and health inequalities have tended not to use longitudinal study designs to incorporate a life course perspective and have instead largely relied on contemporaneous analysis using cross-sectional data. This is problematic because we know that people move between places over time (to places more or less supportive for good health), particularly earlier and later in life, which is likely to affect subsequent health outcomes. Places also evolve in response to macro-level processes such as industrial restructuring, land use changes, urban expansion, redevelopment and regeneration initiatives, or gentrification. Local particularities also mediate relations through the local resources, rules, and practices, which in turn can reinforce and rework place-based characteristics. People make places as much as places make people. The few 
studies that have incorporated area-level constructs into life course accounts of health have tended to use measures of neighbourhood socioeconomic disadvantage, usually obtained from past censuses (Curtis 2004; Murray et al 2012). This work has been instructive in demonstrating that neighbourhood-level socioeconomic conditions in childhood and early life affect health and health inequalities later in life. Yet, the reliance on census-based measures has been insufficient to capture the multiple pathways through which place can influence health inequalities (which, as outlined in the discussion of complexity, seems increasingly necessary).

It is therefore clear that integrating longitudinal environmental information with population data, which identifies health and socioeconomic information, as well as geographical location, is likely to offer important insights into placehealth relations, including a more sophisticated understanding of the way in which places affect health inequalities. One of the key challenges to incorporating a temporal dimension is the significant exertion required in obtaining place-based or environmental data over time. It is rare that long-term area-level environmental data, such as on housing, green space, community resources, or pollution levels, are collected and archived, especially in a digital format. Nonetheless, we contend that the extent of recoverable historical data for small areas has not been fully appreciated. Our investigations suggest that there may be a vast cache of small area data that might enable the reconstruction of past urban environments for use in work on life course, place, and health inequalities. Linking meaningful area-level information and cohort data remains an important research need that offers considerable analytical possibilities.

Work in the field of 'Historical Geographical Information Systems (GIS)' offers the possibility of recreating neighbourhood environments over time. GIS software and geospatial methods have already been adopted to contribute to aspects of historical scholarship. For instance, it is possible to collect placebased data from various historical sources to capture environmental characteristics that potentially affect health, and incorporate this information into a GIS. Once integrated into a GIS it is feasible to develop neighbourhood measures of the health-related environment at particular time points. A recent pilot project in the Edinburgh region of Scotland examined a range of historical data sources including censuses, paper maps, aerial photographs, tabular land use data, city plans, and others to consider the feasibility of developing a series of neighbourhood-level health-related measures at different time points over the past 100 years. The Edinburgh region was selected because it coincided with the geographical extent of the Lothian Birth Cohorts of 1921 and 1936 (Deary et al 2012); the intention for the future is to append small area longitudinal data to the cohort. The pilot work demonstrated the feasibility of obtaining a number 
of measures of the local environment relating to the physical features of neighbourhoods and the resources within them (e.g. public parks). Extracting historical information relating to the experiential environment (e.g. social cohesion) was more challenging. Once the data have been digitally captured and incorporated into a GIS, it was possible to operationalize small area measures of the health-related environment over time, and to build up a 'life course of place'.

In summary, collaboration between geographers, public health researchers, and those with interests in historical GIS offers potential for understanding the significance of place-based factors for health inequalities. The use of archival material for estimating environmental exposure over the life course offers analytical promise. In addition, prospective cohort data collection strategies could usefully consider routinely collecting place-based data that establish the geographical contexts in which people live, work, and play throughout their lives. The diminishing technical and ethical concerns regarding the linking of routine data from various sources (e.g. medical records, census returns, educational reports, social surveys) emphasizes the potential of this approach. In the UK, and elsewhere, there is growing interest amongst researchers, funders, and policymakers in the analytical possibilities offered by utilizing large and complex datasets collected by government departments, the private sector, and other organizations (see for example the ESRC's Big Data Network). Further, prospective cohort studies could usefully examine the opportunities for routinely including environmental data. The integration of longitudinal environmental and health data offers new opportunities for enhancing our understanding of geographical factors that may assist in explaining the establishment of health inequalities over the life course.

\subsection{Resilience, and equigenic environments}

How can thinking about health and place offer both hope for narrowing health inequalities and directions for future research? We know that social and physical environmental characteristics affect health (CSDH 2008), but we have for too long focused solely on which of these characteristics are harmful, how they are harmful, and who is more likely to be exposed to them. There is an alternative. Rather than ask, 'who is at greater risk of being sick and why?', we can ask, 'who seems to stay well, and how do they do that?'. A focus on the positive aspects of health takes many different forms, some with greater relevance to, and evidence from, geographical studies than others. The umbrella of 'positive health' ideas includes notions of salutogenesis (Antonovsky 1979, 1996), positive deviance (Marsh et al 2004), resilience (Bartley 2006; Mitchell 2014; Werner 1996), and assets-based approaches (Morgan and Ziglio 2007), whilst acknowledging that 
each of these terms has its own focus, history, and definition (see also Chapter 15). This focus on how people stay well can be an inspiration for thinking about how health inequalities might be minimized and what the role of place might be. Much of the existing perspectives are focused on socioeconomic inequalities in health, and we consider these first and foremost later in the chapter.

The underlying concept is that some environments, or environmental characteristics, could disrupt the usual conversion of adversity to poor health. Pearson and colleagues (2013) propose a useful framework for considering how this might work. They note that both the neo-material path and the psychosocial path to health inequalities could be affected by environmental characteristics. Places might either reduce exposure to health-damaging things or increase exposure to health-promoting things. Examples of health-promoting social environments could include those which are socially cohesive and supportive, with little or no social segregation and with good and equally accessible health services. Examples of health-promoting physical environments could include those that promote physical activity, that have low levels of pollution, and that offer and promote access to nature. The multiple aspects of environmental influence on health support the ecological public health perspective.

Wealthier people often use their material advantage to buy access to environments which minimize health-related harms or maximize health-related benefits. Yet, it is important to recognize that their wealth is not directly paying for the environmental characteristics they enjoy. They do not, as individuals, pay for their clean air, their walkable street network, their park, or their active social interaction. Affluence buys them residence and participation in places which already have those characteristics (though their presence and influence as residents may then reinforce and protect these characteristics). Where such environmental characteristics are available to less advantaged people, their health can benefit too. Indeed, there is evidence to suggest that some salutogenic environmental characteristics are of greater health benefit to less advantaged people than to their more advantaged neighbours (Lachowycz and Jones 2014). It thus becomes possible that features of the social, physical, or service environments could act to create health equality within the confines of existing material inequality. We call this equigenesis (Mitchell 2013). Equigenic environments could reduce inequalities between places, and/or within them.

A small number of studies have explored these ideas. Studies have, for example, shown that health inequalities are narrower in areas with ready access to urban green spaces, and that the benefits of contact with nature appear stronger for more deprived populations than for more affluent (Mitchell and Popham 2008). Focusing on geographical research, a larger number of studies has looked for 'resilient' areas, defined as having relatively good health given a high level of 
socioeconomic deprivation (Cairns et al 2012; Mitchell et al 2009; Pearson et al 2013; Tunstall et al 2007; van Hooijdonk et al 2007). These studies have found geographically defined populations which face long-term socioeconomic deprivation, yet appear to have significantly better health outcomes than their economic or environmental peers. Mixed methods research, for example, suggests that strong local social cohesion, demographic stability, local housing policies, and physical environments were all implicated in their apparent resilience (Leipert and Reutter 2005; Mitchell et al 2009).

It is important to recognize though, that resilient places are, by definition, rare. Some studies also suggest that, whilst health in these places may be better than in other places facing similar kinds of adversity, it is still often worse than in places not facing adversity at all (Tunstall et al 2007). It also appears that what is a recipe for resilience in one place does not always work in another. Pearson et al note 'some factors may be associated with positive health outcomes in some neighbourhoods, but not in other areas. These findings highlight the importance of the interactions between people and their neighbourhoods, rather than simply the presence of certain factors.... Simply altering environments may not actually change behaviours or outcomes' (2013, p. 244). Other studies have argued that passive 'receipt' of health advantage does not simply stem from residence in a resilient area.

Research has also looked at resilience as a process, though this work has tended to focus on individuals more than places (Canvin et al 2009; Massey et al 1998; Schoon 2006). Such studies are in contrast to those which simply look for places that have achieved a particular 'outcome', like a relatively good mortality rate, despite facing adversity. Studies of process are able to explore the strategies used to mitigate the impacts of adversity, without a need to define a 'successful' outcome. This work (usually qualitative) is often far more nuanced than the outcome studies and reveals the complex trajectories which people living in poverty experience. As Batty and Cole argue: 'It is more useful to see resilience as a process of meeting successive challenges-in which some people are able to make incremental gains that extend the opportunities open to them despite the relentlessness of the financial challenges they face' (2010, p. 47). There are also longitudinal mixed methods and quantitative studies of individuals who face adversity, which have been able to explore the processes by which resilience manifests itself (or not) (see, for example, Conger and Conger 2002, and Werner 1996), but we note a general lack of such studies about places or communities. Such studies might better explore how the characteristics of places help or hinder positive outcomes from adverse situations.

The idea of focusing on how some people stay well is controversial (Harrison 2013; MacKinnon and Derickson 2013). A key criticism is that focusing on how 
to mitigate the conversion of economic adversity to poor health, rather than on eliminating economic adversity itself, might implicitly condone economic inequality (for an overview of this perspective, see Chapter 15). Such arguments about the potential political misuse of positive perspectives on health are well made, but the position in which they leave those of us concerned about health inequalities seems perverse. Whilst the structural causes of inequality are clear, progress in reducing it is demonstrably poor. Radical action is not supported by the electorate, which continues to hold a paradoxical opinion on income inequalities and redistribution. About $80 \%$ of the population believe that the income gap between the richest and poorest is too large (Park et al 2013). However, only $40 \%$ say they would actually like income to be redistributed and just 5\% agree that extra spending on welfare benefits (a key lever for reducing poverty) is a high priority for government (Park et al 2013). To argue that reducing material inequalities is the only way to tackle health inequalities is akin to only prescribing a medicine which is not really available. There must be room for alternative agendas.

We should also note that economic situation is far from being the only source of adversity which places face now, and will in the future. The ecological public health perspective reminds us of the risks posed by environmental change and degradation. It is likely that less advantaged places and people will be most at risk from these threats in the future, but all humans are potentially vulnerable (McMichael et al 2008). Understanding how best to foster resilience to these kinds of adversities will be important if we are to avoid the creation of new environmentally based axes of health inequality in the future.

In summary, evidence about the extent to which characteristics of places might disrupt the pathways between poverty and poor health is beginning to emerge from a variety of disciplines. It is currently comparatively sparse, but it holds the promise of something which might actually work to narrow inequalities in health. Searching for equigenic environments should not lead us, or policymakers, to abandon the drive for narrowing material inequalities or preventing ecological catastrophe, but whilst that struggle continues we must examine the possibility that where we live and work might contribute to achieving greater health equality now and in the future.

\subsection{Conclusion: The promise of geographical approaches}

This chapter has argued that geographical approaches have been important in identifying social, political, and environmental drivers of health inequalities. The places in which we live, work, and play throughout our lives, and the geographical 
processes operating through these spaces, are integral to a comprehensive understanding of health inequalities. Using a geographical framing, three nascent and interrelated themes that offer promise in understanding health inequalities have been considered. First, the utility of the concept of EPH was considered. EPH links environmental change to health, and more broadly to a consideration of all aspects of the environment, their interactions, and the casual pathways between the environment and health inequalities. Second, the use of historical data sources to recreate health-related place-based measures over time offers analytical promise. Appending these historical data with cohort information will enable researchers to better understand how environmental factors affect health inequalities over the life course. Finally, the chapter has offered a cautious welcome to the comparatively new idea that some aspects of social and physical environment might, in themselves, play a part in reducing health inequalities by disrupting the usual conversion of socioeconomic adversity to poor health. Whilst, like others in this book (Chapter 15), we are concerned that such a focus could legitimize reductions in effort to tackle socioeconomic inequalities themselves, we believe that the potential of equigenic environments must be explored.

\section{References}

Antonovsky, A. (1979) Health, Stress and Coping. San Francisco: Jossey-Bass.

Antonovsky, A. (1996) The salutogenic model as a theory to guide health promotion. Health Promotion International, 11(1): 11-18.

Bartley, M. (ed.) (2006) Capability and resilience: Beating the odds. London: UCL.

Batty, E., and Cole, I. (2010) Resilience and the Recession in Six Deprived Communities: Preparing for Worse to Come. York: Joseph Rowntree Foundation.

Brofenbrenner, U. (1979) The Ecology of Human Development. Cambridge, MA: Harvard University Press.

Buck, D., and Frosini, F. (2012) Clustering of Unhealthy Behaviours Over Time: Implications for Policy and Practice. London: King's Fund.

Cairns, J. M., Curtis, S. E., and Bambra, C. (2012) Defying deprivation: A cross-sectional analysis of area level health resilience in England. Health and Place, 18(4): 928-933.

Canvin, K., Marttila, A., Burstrom, B., and Whitehead, M. (2009) Tales of the unexpected? Hidden resilience in poor households in Britain. Social Science and Medicine, 69(2): $238-245$.

CSDH (2008) Closing the gap in a generation: Health equity through action on the social determinants of health. Final report of the CSDH. Geneva: WHO.

Conger, R. D., and Conger, K. J. (2002) Resilience in Midwestern families: Selected findings from the first decade of a prospective, longitudinal study. Journal of Marriage and Family, 64(2): 361-373.

Curtis, S. (2004) Health and Inequality: Geographical Perspectives. London and Thousand Oaks, CA: Sage.

Dahlgren, G., and Whitehead, M. (1991) Policies and Strategies to Promote Social Equity in Health. Stockholm: Institute of Futures Studies. 
Dean, K. (1993) Integrating theory and methods in population health research. In K. Dean (ed.), Population Health Research: Linking Theory and Methods. London: Sage Publications.

Deary, I. J., Gow, A. J., Pattie, A., and Starr, J. M. (2012) Cohort profile: The Lothian Birth Cohorts of 1921 and 1936. International Journal of Epidemiology, 41(6): 1576-1584.

Galster, G. C. (2011) The mechanism(s) of neighbourhood effects: Theory, evidence, and policy implications. In M. Van Ham, D. Manley, N. Bailey, L. Simpson, and D. Maclennan (eds), Neighbourhood Effects Research: New Perspectives. New York: Springer.

Gatrell, A. C. (2011) Mobilities and Health. Farnham, Surrey and Burlington, VT: Ashgate.

Hanlon, P., Carlisle, S., Hannah, M., Reilly, D., and Lyon, A. (2011) Making the case for a 'fifth wave' in public health. Public Health, 125(1): 30-36.

Harrison, E. (2013) Bouncing back? Recession, resilience and everyday lives. Critical Social Policy, 33(1): 97-113.

Hunter, D. J. (2009) Leading for health and wellbeing: The need for a new paradigm. Journal of Public Health, 31(2): 202-204.

Katikireddi, S. V., Higgins, M., Smith, K. E., and Williams, G. (2013) Health inequalities: The need to move beyond bad behaviours. Journal of Epidemiology and Community Health, 67(9): 715-716.

Lachowycz, K., and Jones, A. P. (2014) Does walking explain associations between access to greenspace and lower mortality? Social Science and Medicine, 107(1): 9-17.

Leipert, B. D., and Reutter, L. (2005) Developing resilience: How women maintain their health in northern geographically isolated settings. Qualitative Health Research, 15(1): 49-65.

MacKinnon, D., and Derickson, K. D. (2013) From resilience to resourcefulness: A critique of resilience policy and activism. Progress in Human Geography, 37(2): 253-270.

Marsh, D. R., Schroeder, D. G., Dearden, K. A., Sternin, J., and Sternin, M. (2004) The power of positive deviance. British Medical Journal, 329(7475): 1177-1179.

Massey, S., Cameron, A., Ouellette, S., and Fine, M. (1998) Qualitative approaches to the study of thriving: What can be learned? Journal of Social Issues, 54(2): 337-355.

McLaren, L., and Hawe, P. (2005) Ecological perspectives in health research. Journal of Epidemiology and Community Health, 59(1): 6-14.

McMichael, A. J., Friel, S., Nyong, A., and Corvalan, C. (2008) Global environmental change and health: Impacts, inequalities, and the health sector. British Medical Journal, 336(7637): 191-194.

Mitchell, R. (2013) What is equigenesis and how might it help narrow health inequalities? [Online]. Edinburgh: Centre for Research on Environment, Society and Health. Available from http://cresh.org.uk/2013/11/08/what-is-equigenesis-and-how-might -it-help-narrow-health-inequalities/ (accessed on 9 June 2014).

Mitchell, R. (2014) Population resilience. The Wiley Blackwell Encyclopedia of Health, Illness, Behavior, and Society. John Wiley and Sons, Ltd.

Mitchell, R., Gibbs, J., Tunstall, H., Platt, S., and Dorling, D. (2009) Factors which nurture geographical resilience in Britain: A mixed methods study. Journal of Epidemiology and Community Health, 63(1): 18-23.

Mitchell, R., and Popham, F. (2008) Effect of exposure to natural environment on health inequalities: An observational population study. The Lancet, 372: 1655-1660. 
Morgan, A., and Ziglio, E. (2007) Revitalising the evidence base for public health: An assets model. Global Health Promotion, 14(1): 17-22.

Murray, E. T., Southall, H., Aucott, P., Tilling, K., Kuh, D., Hardy, R., and Ben-Shlomo, Y. (2012) Challenges in examining area effects across the life course on physical capability in mid-life: Findings from the 1946 British Birth Cohort. Health and Place, 18(2): 366-374.

Park, A., Bryson, C., Clery, E., Curtice, J., and Phillips, M. (2013) British Social Attitudes: The 30th Report. London: National Centre of Social Research.

Pearce, J. (2013) An environmental justice framework for understanding neighbourhood inequalities in health and well-being. In D. Manley, M. van Ham, N. Bailey, L. Simpson, and D. Maclennan (eds), Neighbourhood Effects of Neighbourhood-based Problems? A Policy Context. Dordrecht: Springer Press, pp. 89-112.

Pearce, J., and Dorling, D. (2009) Tackling global health inequalities: Closing the health gap in a generation. Environment and Planning A, 41(1): 1-6.

Pearce, J., and Dorling, D. (2010) The influence of the selective migration patterns of smokers and non-smokers on geographical inequalities in health. Annals of the Association of American Geographers, 100(2): 393-408.

Pearce, J., Richardson, E., Mitchell, R., and Shortt, N. (2010) Environmental justice and health: The implications of the socio-spatial distribution of multiple environmental deprivation for health inequalities in the United Kingdom. Transactions of the Institute of British Geographers, 35(4): 522-539.

Pearson, A. L., Pearce, J., and Kingham, S. (2013) Deprived yet healthy: Neighbourhoodlevel resilience in New Zealand. Social Science and Medicine, 91: 238-245.

Rayner, G. (2009) Conventional and ecological public health. Public Health, 123(9): 587-591.

Rayner, G., and Lang, T. (2012) Ecological Public Health: Reshaping the Conditions for Good Health. Oxon: Routledge.

Rosenberg, M. (2014) Social justice, idealist theory, health and health care. Progress in Human Geography, 38(3): 466-475.

Schoon, I. (2006) Risk and Resilience: Adaptations in Changing Times. Cambridge University Press.

Thomas, B., Dorling, D., and Smith, G. D. (2010) Inequalities in premature mortality in Britain: Observational study from 1921 to 2007. British Medical Journal, 341: c3639.

Tunstall, H., Mitchell, R., Gibbs, J., Platt, S., and Dorling, D. (2007) Is economic adversity always a killer? Disadvantaged areas with relatively low mortality rates. Journal of Epidemiology and Community Health, 61(4): 337-343.

Van Hooijdonk, C., Droomers, M., Van Loon, J. A. M., Van der Lucht, F., and Kunst, A. E. (2007) Exceptions to the rule: Healthy deprived areas and unhealthy wealthy areas. Social Science and Medicine, 64(6): 1326-1342.

Wacquant, L. J. D. (2008) Urban Outcasts: A Comparative Sociology of Advanced Marginality. Cambridge: Polity Press.

Werner, E. E. (1996) Vulnerable but invincible: High risk children from birth to adulthood. European Child and Adolescent Psychiatry, 5(Suppl. 1): 47-51. 